\title{
Condom gap in Africa: evidence from donor agencies and key informants
}

\author{
James D Shelton, Beverly Johnston
}

Public discussions on combating HIV in Africa seem to be focusing on antiretroviral drugs rather than condoms, which are the mainstay of prevention. ${ }^{1}$ In sub-Saharan Africa most condoms are bought with funds from donors, although a few countries (such as South Africa and Botswana) buy them from national funds. We assessed provision of condoms in these countries.

\section{Methods and results}

We obtained data from UNFPA (the United Nations agency responsible for providing condoms) on condoms paid for by donors and further refined it with information from United States Agency for International Development's commodity tracking system. We also sought data from about 12 key informants knowledgeable on condom provision in Africa.

Provision of condoms by donors remained surprisingly constant (400-500 million per year) over the past five years. The numbers fell from just over 600 million in 1995 to about 340 million in 1998 before rising again to just over 500 million in 1999. In addition, by 1999 roughly 210 million condoms were purchased by countries' own funds. This amounts to a total of about 724 million condoms or only 4.6 condoms per man aged 15-59 years in sub-Saharan Africa.

Level of provision varied widely. Provision in the six countries with highest levels (Botswana, South Africa, Zimbabwe, Togo, Congo, and Kenya) averaged about 17 condoms per man aged 15-59. If that level of provision were replicated for all 156 million sub-Saharan African men, annual provision would be 2.65 billion. This corresponds to a "condom gap" of roughly 1.9 billion a year (figure).

\section{Comment}

We found that the overall provision of condoms was 4.6 per man per year, which seems low. Another 1.9 billion condoms need to be provided a year for all countries to equal the level of provision of the six highest providing countries.

We may have overestimated the condom gap since we omitted the commercial sector and probably missed some national government and donor support. However, given the resource poor environments in Africa, we believe our rough estimate missed only a small proportion of condoms. The true gap could be considerably larger than our estimate because the need may be larger than 17 condoms per man and the population in Africa is still growing.

How much would it cost to close the 1.9 billion condom gap for sub-Saharan Africa? At the international price of $\$ 0.025$ per condom, the annual cost would be only $\$ 47.5 \mathrm{~m}(£ 34 \mathrm{~m})$. However, as with drugs

to treat HIV, the commodity costs are only the beginning. Service delivery costs (including promotion) are a greater challenge. Nevertheless, effective models for delivery are known and much infrastructure is in place or can be scaled up through existing successful mechanisms such as condom social marketing and clinics. ${ }^{2}$

But health programming of any sort requires concerted effort and resources. Finding ways to promote condom use and other prevention among high transmitting people is particularly important. Experience in Thailand shows such an approach can greatly reduce sexually transmitted infection and HIV.

Relative to the enormity of the HIV/AIDS pandemic in Africa, providing condoms is cheap and cost effective. All aspects of HIV control are important, but a first priority must be prevention.

The views expressed are solely those of the authors and not necessarily those of USAID. We thank Steve Hawkins for help with data and a critique of the paper and John Stover, John Ross, and Randy Bulato for technical insights.

Contributors: JDS conceived the analysis, directed the overall data collection, and led writing the paper. BJ had primary responsibility for collecting and compiling data and helped write the paper. JDS is the guarantor.

Funding: USAID

Competing interests: None declared.

1 Sidley P. South African court battle damages drug industry's image. $B M$ J 2001;322:635.

2 Gardner R, Blackburn RD, Upadhyay UD. Closing the condom gap. Baltimore: Johns Hopkins University School of Public Health, Population Information Program, 1999. (Population reports, series H, No 9.)

3 Hanenberg RS, Rojanapithayakorn W, Kunasol P, Sokal D. Impact of Thailand's HIV-control programme as indicated by the decline in sexually transmitted diseases. Lancet 1994;344:243-5.

(Accepted 13 June 2001)
See also Editorial by

Verheul and Rowson and Education and debate p 152

Center for

Population, Health and Nutrition, US

Agency for

International Development, Washington, DC 20523, USA

James D Shelton senior medical scientist

Futures Group International, Population, Health and Nutrition Information Project, 600 13th Street, NW, Washington, DC 20005, USA

Beverly Johnston senior researcher

Correspondence to: J D Shelton

Jshelton@

USAID.gov

BMJ 2001;323:139 